\title{
Correction to: A proposed "Radiological Evaluation Score for Bone Tumors" (REST): An objective system for assessment of a radiograph in patients with suspected bone tumor
}

\author{
A. A. Salunke ${ }^{1}$ (D) K. Nandy ${ }^{1}$ K. Puj ${ }^{1} \cdot$ M. Kamani ${ }^{1}$ S. Pathak ${ }^{3} \cdot$ J. Shah $^{4} \cdot$ R. H. Bhalerao ${ }^{5} \cdot$ A. Jain ${ }^{1} \cdot$ M. Sharma $^{1}$. \\ V. Warikoo ${ }^{1} \cdot$ K. Patel ${ }^{1} \cdot$ P. Rathod ${ }^{1} \cdot$ S. Bhatt ${ }^{1} \cdot$ T. Tank $^{2} \cdot$ S. Pandya ${ }^{1}$
}

Published online: 14 June 2021

(C) Istituto Ortopedico Rizzoli 2021

\section{Correction to: MUSCULOSKELETAL SURGERY https://doi.org/10.1007/s12306-021-00711-0}

The original version of this article unfortunately contained a mistake. The affiliations of the authors have been wrongly mentioned.

The correct affiliation of the following authors should be:

K.Nandy ${ }^{1}$ K.Puj ${ }^{1}$ M.Kamani ${ }^{1}$ A.Jain ${ }^{1}$ M.Sharma ${ }^{1}$

V.Warikoo $^{1}$ K.Patel $^{1}$ P.Rathod ${ }^{1}$ S.Bhatt $^{1}$ S.Pandya $^{1}$

${ }^{1}$ Department of Surgical Oncology, Gujarat Cancer Research Institute (GCRI), Ahmedabad, Gujarat, India
Publisher's Note Springer Nature remains neutral with regard to jurisdictional claims in published maps and institutional affiliations.

The original article can be found online at https://doi.org/10.1007/ s12306-021-00711-0.

A. A. Salunke

drabhijeetsalunke@gmail.com

1 Department of Surgical Oncology, Gujarat Cancer Research Institute (GCRI), Ahmedabad, Gujarat, India

2 Department of Anesthesia, Gujarat Cancer Research Institute (GCRI), Ahmedabad, Gujarat, India

3 Department of Orthopedics, MM Institute of Medical Sciences \& Research, Ambala, India

4 Osteo Care - Ortho Onco Clinic, Ahmedabad, Gujarat, India

5 Department of Electrical Engineering and Computer Science, Institute of Infrastructure, Technology, Research And Management, Ahmedabad, Gujarat, India 